\title{
Optimal Duration of Sun Exposure for Adequate Cutaneous Synthesis of Vitamin D in Indian Cities: An Estimate Using Satellite-Based Ultraviolet Index Data
}

\author{
Little Flower Augustine ${ }^{1}$, K Madhavan Nair ${ }^{2}$ and Bharati Kulkarni ${ }^{3 *}$ \\ ${ }^{1}$ ICMR-Post doctoral Research Fellow, Division of Clinical studies, ICMR-National Institute of Nutrition, India
}

${ }^{2}$ ICMR-National Institute of Nutrition, India

${ }^{3}$ Division of Clinical studies, ICMR-National Institute of Nutrition, India

Received: June 18, 2018; Published: June 27, 2018

*Corresponding author: Bharati Kulkarni, Division of Clinical Studies, National Institute of Nutrition, Indian Council of Medical research, JamaiOsmania PO, Hyderabad 500007, Telangana, India

\begin{abstract}
Lack of region specific guidelines on sun exposure for acquiring optimal vitamin D could be a bottle neck for developing effective education strategies for Indian population. We calculated the required sun exposure time for each day for one year considering $10 \%$ exposure, type V skin accounting for $1000 \mathrm{IU}$ of vitamin D per day for clear and cloudy sky conditions. The UV Index provided by TEMIS satellite for 10 Indian stations ranging in latitude from 8 degree to 38 degrees for 1 year were obtained, and were converted to the vitamin D effective UV radiation, applied minimal erythemal doses and Holicks rule. Attenuation of UV radiation due to clouds was accounted for by using data on daily clouds measured in octas from Agricultural meteorology database. The seasonal variations were also accounted for. Our data showed a latitude-dependent change in sun exposure time. A seasonal variation was also observed. After accounting for clouds, an exposure of 30-35 minutes appeared to be sufficient in all stations except for Srinagar. Seasonal variations were high in stations ranging from 14 minutes to 133 minutes. About 75 $\%$ of the days were conducive for sun exposure in the stations studied. The estimated sun exposure time, if validated, can be a useful tool for behavioural change communication facilitating safe sun exposure for satisfying vitamin D status in tropical countries like India.
\end{abstract}

Keywords: Vitamin D from sun exposure; India; Estimated Duration of Exposure

\section{Introduction}

Vitamin D is essential for stimulating intestinal calcium and phosphorus absorption, bone calcium mobilization, and increasing renal re-absorption of calcium in the distal tubule and therefore very important for the bone metabolism [1]. In a tropical country like India, where dietary sources of vitamin D are meagre, and fortification is expected to satisfy less than one -third of recommended dietary allowance, sun exposure continues to be the major source for vitamin D. However, studies in India have reported a very high prevalence of vitamin D deficiency (60-75 \%,) [2,3]. Several factors have been implicated for the high prevalence of vitamin D deficiency such as the latitude, season, atmospheric components, clothing, sunscreen use and skin pigmentation, as well as age and high Body mass index [4,5]. Apart from these factors, information on how long to expose to get adequate vitamin D during different seasons is relatively lower [6]. There have been reports from countries of northern latitudes wherein, the UV data has been successfully simulated to arrive at estimates of sun exposure all through the year
$[7,8]$. However, such an attempt has never been done in India. The estimates are important since it would guide the population for optimal sun exposure in the current environmental and cultural scenario. It would also guide researchers in deciding on the duration of interventions aimed at improving vitamin D status through sun exposure. The aim of the current study was therefore, to estimate the duration of sun exposure required for cutaneous synthesis of vitamin D in Indian cities using TEMIS satellite UV Index data, the only data available currently from India for this estimate.

\section{Materials and Methods \\ UV Index -TEMIS Data Base}

Using TEMIS (Tropospheric Emission Monitoring Internet Service of European Space Agency) satellite data, Ultra Violet Index (UV Index) was computed [9]. The action spectrum used was proposed by McKinlay \& Diffey (1987) and later adopted as a standard by International Commission on Illumination [10]. It is an integra- 
tion of the UV irradiance at the ground (290-400 nm) weighted by spectral action function ( 1 unit equals $25 \mathrm{~mW} / \mathrm{m}^{2}$ ). The UV Index was obtained by dividing the erythemal action spectrum weighted irradiance by $25 \mathrm{mWm}^{2}$. The reference year considered was January 2016 to December 2016 and during this period, data for 10 stations in India was available with TEMIS, for 310-320 days, valid for clear-sky conditions. For October, wherein cloud-data was not available for 2016, the available data for 2015 was considered.

a) Latitude -Dependent Changes and Seasonal Variations in Sun Exposure Time: Latitude dependent changes were calculated for clear sky from daily data for 1 year starting from January 2016 to December 2016.

b) Conversion of Erythemal Action Spectrum to Vitamin D Action Spectrum: Minimal erythemal dose (MED) is the quantity of erythema-effective energy (expressed as Joules per square meter) required to produce the first perceptible, skin redness reaction with clearly defined borders. The vitamin D action spectrum has higher weighting coefficients in UV-B than the erythemal action spectrum, while the latter is more sensitive to UV-A than the former. Therefore, a factor has been applied for conversion of erythemal action spectrum weighted UV to vitamin $\mathrm{D}$ weighted action spectrum. This was done by using the ratio calculated as Ratio $=2-\mathrm{e}^{0.25-\mathrm{uv} / 2.5}$, where UVI is the UV index [11]. The vitamin D effective UV has been calculated using the formula, UVD = R X UVE. ie, $25 \mathrm{~mW} \mathrm{~m}^{-2} \mathrm{X}\left(2-\mathrm{e}^{0.25-\mathrm{UVI} / 2.5}\right)$, where $\mathrm{R}$ is the ratio of conversion of erythemally effective UV to vitamin D effective UV radiation, UVD is vitamin D effective UV and UVE is erythemally effective UV radiation in $\mathrm{W} / \mathrm{m}^{2}$ and UVI is UV index [11]. Equivalency with oral dose of vitamin D: Holicks rule of one fourth MED over $25 \%$ body exposure providing 1000 IU was applied [12].

c) Computation of Exposure Time based on Skin Type: The differences in skin types were accounted for by the use of MED response, which are derived based on the response of skin to UV till redness. The MEDs are in the range of $300 \mathrm{~J} / \mathrm{m}^{2}$ for skin type III, $450 \mathrm{~J} / \mathrm{m}^{2}$ for IV and $600 \mathrm{~J} / \mathrm{m}^{2}$ for $\mathrm{V}$, the exposure time increasing in the order of increasing skin pigmentation 8. For the calculations, skin type $\mathrm{V}$ was considered. d) Computation of Exposure Time based on Variations in \% Body Surface Area (BSA) Exposure: Body surface area exposure of $10 \%$ was considered corresponding to face and forearm. These considerations were based on Indian culture specific dressing patterns [13].

e) Use of Daily Cloud Cover for Estimating UV Index to Mimic Real-Life Situation- Agrimet Data Base: Apart from estimating duration of sun exposure for clear sky conditions, cloud modifying

factors have been applied to account for cloud cover of sky which is known to attenuate UV insolation. Cloudiness of sky is represented in terms of octas, ranging from 0-8 with $>7$ indicating an overcast sky. The daily octas for each station was obtained from agricultural meteorology department website (http://imdagrimet. gov.in/imd_datalist/form) and daily data was obtained for 12 months (312-323 days) representing 4 seasons i.e. winter, hot/ pre-monsoon, summer/monsoon, post-monsoon).The UV index for clear sky (UVI0) was converted to include cloud cover by using the formula UVI $=\mathrm{UVI}_{0} \mathrm{XCMFX}(1+0.08 \mathrm{X} \Delta \mathrm{H})$, where CMF is the Cloud Modification Factor and $\Delta \mathrm{H}$ is the difference in altitude (in $\mathrm{km}$ ) from where UVI0 is referring to; in this case it is 0,1 for $0-2,0.8$ for 3-4, 0.5 for 5-6 and 0.2 for 7-8 octas of clouds [14].

\section{Seasonal Variations of UV Index in Indian Cities}

To get an overview on the seasonal variations of UV Index in Indian cities, the seasonal classification suggested by Indian Meteorology Division (IMD) was applied i.e. Winter Season: January-February.

a) Pre Monsoon Season: March - May, Southwest Monsoon Season: June-September, Post Monsoon Season: October - December. The daily UV index values were averaged for a particular season. The UV Index values were interpreted based on the criteria i.e. 1-4, no risk; 5, low risk; 6-9, medium risk and 10 onwards is considered to be high risk suggested by System of Air Quality and Weather Forecasting And Research, Government of India [15]. Estimate of days with risk of overexposure: The numbers of days which have a risk of over-exposure were calculated based on the UV Index data for clear sky and accounted for cloudy sky.

\section{Results}

Table 1: Sun exposure time in minutes for cutaneous synthesis of 1000 IU of vitamin D (considering $10 \%$ body surface area exposure) in Indian cities, compiled data for clear and cloudy sky conditions.

\begin{tabular}{|c|c|c|c|c|c|c|c|c|c|}
\hline \multirow[b]{2}{*}{ Stations } & \multicolumn{5}{|c|}{ Clear Sky } & \multicolumn{4}{|c|}{ Accounted for clouds } \\
\hline & Latitude & $\mathrm{N}$ & Mean & SD & $95 \%$ CI & $\mathrm{N}$ & Mean & SD & $95 \%$ CI \\
\hline Chennai & 13008 & 321.00 & 11.3 & 1.90 & $11.1-11.5$ & 311.00 & 32.2 & 27.32 & $29.1-35.2$ \\
\hline Bangalore & 12097 & 322.00 & 10.8 & 1.80 & $10.6-11.0$ & 308.00 & 32.5 & 25.25 & $29.7-35.3$ \\
\hline Bhopal & 23028 & 322.00 & 14.3 & 4.89 & $13.8-14.9$ & 305.00 & 28.6 & 24.47 & 25.9-31.4 \\
\hline Hyderabad & 17037 & 323.00 & 11.9 & 2.75 & $11.6-12.2$ & 308.00 & 32.0 & 25.20 & $29.2-34.8$ \\
\hline Kolkata & 22050 & 324.00 & 14.3 & 4.65 & $13.8-14.8$ & 309.00 & 30.8 & 27.34 & $27.7-33.8$ \\
\hline Mumbai & 18093 & 322.00 & 12.8 & 3.30 & $12.4-13.1$ & 307.00 & 31.0 & 23.81 & $28.3-33.7$ \\
\hline Ahmedabad & 23005 & 320.00 & 14.5 & 4.82 & $14.0-15.1$ & 308.00 & 24.9 & 17.91 & $22.9-26.9$ \\
\hline
\end{tabular}




\begin{tabular}{|c|c|c|c|c|c|c|c|c|c|}
\hline Pune & 18052 & 323.00 & 12.3 & 3.09 & $11.9-12.6$ & 308.00 & 30.2 & 24.04 & $27.5-32.9$ \\
\hline Delhi & 28062 & 322.00 & 18.7 & 8.73 & $17.7-19.6$ & 309.00 & 29.3 & 26.39 & $26.3-32.2$ \\
\hline Srinagar & 34013 & 315.00 & 22.3 & 14.29 & $20.7-23.9$ & 308.00 & 63.3 & 78.60 & $54.5-72.1$ \\
\hline
\end{tabular}

Table 2: Season-wise variations in sun exposure time, for cutaneous synthesis of 1000 IU of vitamin D (considering $10 \%$ body surface area exposure) in Indian cities, compiled data for clear and cloudy sky conditions.

\begin{tabular}{|c|c|c|c|c|c|c|c|c|}
\hline \multirow[t]{2}{*}{ Stations } & \multicolumn{2}{|c|}{ Winter } & \multicolumn{2}{|c|}{ Summer } & \multicolumn{2}{|c|}{ Monsoon } & \multicolumn{2}{|c|}{ Post-monsoon } \\
\hline & Mean \pm SD & $95 \%$ CI & Mean \pm SD & $95 \%$ CI & Mean \pm SD & $95 \%$ CI & Mean \pm SD & $95 \%$ CI \\
\hline Bangalore & $20.3 \pm 19.88$ & $14.3-26.4$ & $18.4 \pm 15.67$ & $14.7-22.0$ & $45.5 \pm 22.19$ & $41.3-49.8$ & $34.4 \pm 28.92$ & 28.1-40.7 \\
\hline Chennai & $19.3 \pm 14.40$ & $15.1-23.60$ & $17.1 \pm 11.2$ & $14.5-19.7$ & $36.8 \pm 25.25$ & $31.9-41.6$ & $46.5 \pm 34.99$ & $38.9-54.2$ \\
\hline Hyderabad & $27.1 \pm 27.11$ & $18.9-35.2$ & $18.1 \pm 14.78$ & $14.7-21.5$ & $49.1 \pm 22.72$ & 44.7-53.4 & $25.0 \pm 22.60$ & $20.0-29.9$ \\
\hline Mumbai & $20.5 \pm 21.60$ & $14.0-27.1$ & $16.3 \pm 11.5$ & $13.6-19.0$ & $52.2 \pm 21.6$ & 48.1-56.3 & $21.7 \pm 14.91$ & $18.4-24.9$ \\
\hline \multicolumn{9}{|l|}{ Bhopal } \\
\hline Pune & $20.6 \pm 15.4$ & $15.8-25.3$ & $17.7 \pm 16.29$ & $13.9-21.5$ & $46.7 \pm 22.50$ & $42.4-50.9$ & $24.5 \pm 23.7$ & $19.4-29.7$ \\
\hline Kolkata & $29.5 \pm 29.15$ & $20.7-38.4$ & $20.1 \pm 18.87$ & $15.7-24.5$ & $38.9 \pm 24.46$ & $34.2-43.5$ & $30.2 \pm 32.7$ & 23.1-37.37 \\
\hline Ahmedabad & $22.3 \pm 8.41$ & $19.8-24.9$ & $15.5 \pm 8.97$ & 13.4-17.6 & $36.1 \pm 25.02$ & $31.3-40.8$ & $20.2 \pm 4.06$ & $19.3-21.08$ \\
\hline Delhi & $44.8 \pm 48.18$ & $30.1-59.5$ & $19.5 \pm 13.98$ & $16.2-22.7$ & $34.6 \pm 27.3$ & $28.6-40.6$ & $20.2 \pm 5.65$ & $17.9-22.6$ \\
\hline Srinagar & $133.1 \pm 125.24$ & 94.9-171.1 & $49.9 \pm 43.6$ & $39.8-60.1$ & $26.9 \pm 24.09$ & $22.4-31.6$ & $85.2 \pm 86.2$ & $66.4-104.1$ \\
\hline
\end{tabular}

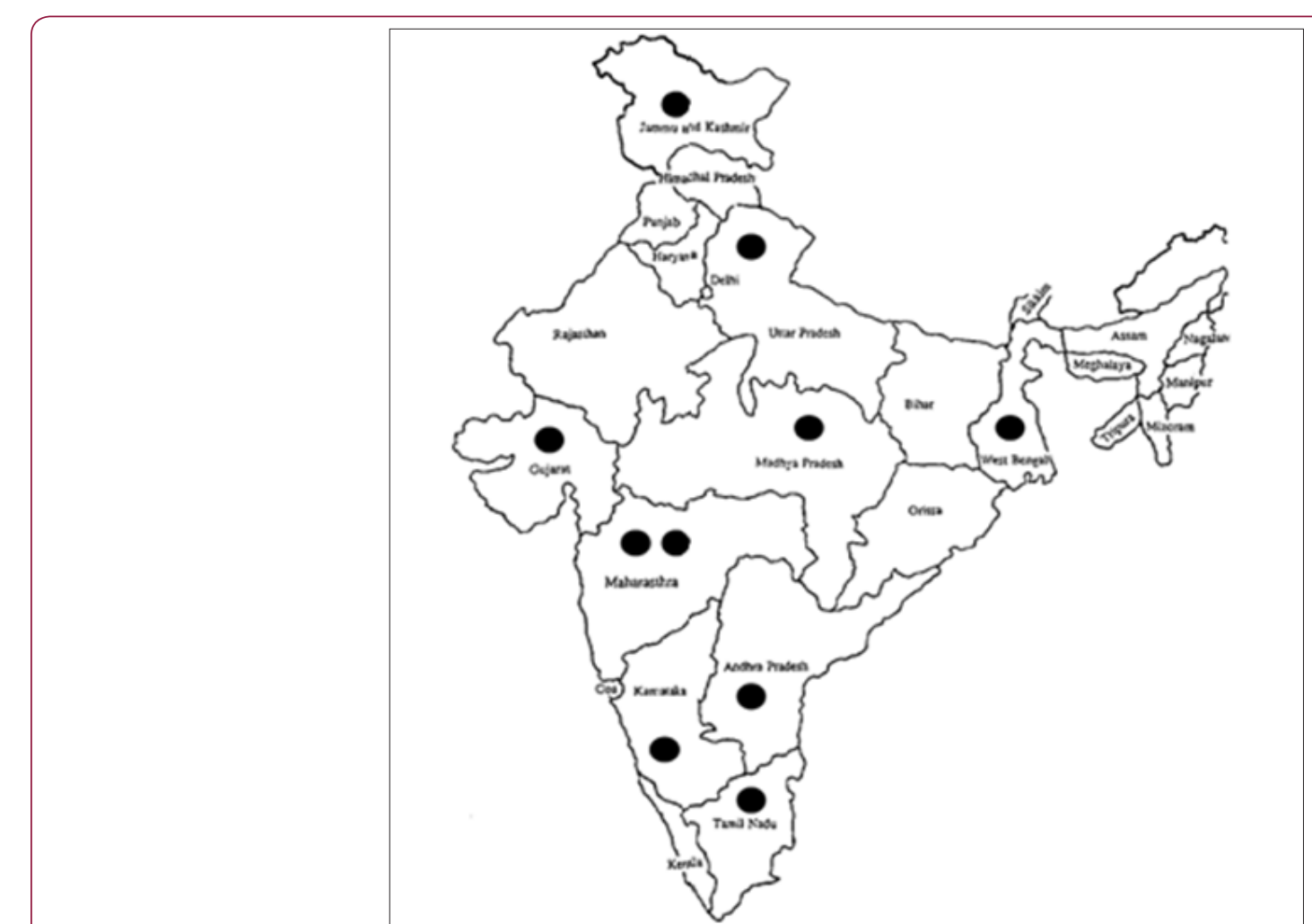

Figure 1: Geographical locations of Indian cities for which TEMIS UV Index data was used for estimating sun exposure time for cutaneous synthesis of vitamin D.

Out of the 10 stations in India for which ultraviolet index data was available, six stations were lying within the tropic of cancer and tropic of Capricorn while four of the stations were beyond this geographic limit. The farthest of the stations was Srinagar (34o13 N). Under clear sky condition, a latitude-dependency was observed in the duration of sun exposure for 1000 IU of vitamin D. The mean duration of exposure ranged between 10.8-22.3 minutes (Table 1). After accounting for cloudy sky conditions wherever applicable, the duration was 1.5 to 3 fold higher in all stations and dependency on latitude was not evident. However, Srinagar (34013 latitude), needed the longest duration of exposure in both clear and cloudy sky conditions (Figure 1). Season-wise estimates showed monsoon and winter seasons requiring maximum exposure time for optimal vitamin D while for Srinagar, it required 133.1 \pm 125.24 during winter and $85.2 \pm 86.2$ minutes during post-monsoon season for 1000 IU vitamin D at noon time. The summer exposure times in tropics 
were $<20$ minutes in the tropical regions. Beyond tropics, the required duration was longer (Table 2). In about $13-24 \%$ of days, the UVI was $>10$. The lowest number of days was in Mumbai and the highest was in Bangalore (Table 3).

Table 3: Number of days in a year with a higher risk of overexposure (UVI >10).

\begin{tabular}{|c|c|c|c|}
\hline Station & $\begin{array}{c}\text { Number of } \\
\text { days UVI>10 }\end{array}$ & $\begin{array}{c}\text { Total no. Of } \\
\text { days }\end{array}$ & \% \\
\hline Bangalore & 74 & 313 & 23.6 \\
\hline Chennai & 72 & 323 & 22.3 \\
\hline Hyderabad & 51 & 323 & 15.8 \\
\hline Bhopal & 75 & 323 & 23.2 \\
\hline Mumbai & 43 & 312 & 13.8 \\
\hline Pune & 65 & 322 & 20.2 \\
\hline Kolkata & 43 & 323 & 13.3 \\
\hline Ahmedabad & 51 & 323 & 15.8 \\
\hline Delhi & 49 & 323 & 15.2 \\
\hline Srinagar & 50 & 312 & 16.1 \\
\hline
\end{tabular}

\section{Discussion}

The present study is first of its kind from India which attempted to estimate the average duration of sun exposure for cutaneous synthesis of vitamin D, utilizing Trophospheric Emission Monitoring Internet Service (TEMIS), the authentic web-based service of European Space Agency. The uniqueness of this study also lies in the translatability of these findings for strengthening the information system on sun exposure for acquiring optimal vitamin D. The estimates have been contextualized to Indian conditions, considering the common skin type (skin type V) and culturally appropriate exposure of body surface area (10\%). Environmental factors such as ozone, altitude, solar zenith angle are embedded in the UV Index calculations and therefore, have been taken care of. Since daily data is available, the seasonal variations could also be accounted for. In addition to this, daily data on clouds have been extracted and used in the calculations for acquiring an estimate closer to real life situations. Therefore, we believe that the calculated sun exposure would provide reasonable estimates in real-life scenario.

Previous studies have used one of the two ways of estimating duration of sun exposure for optimal vitamin D synthesis in skin:

a. Using simulation tools like Fast RT $[7,11,16]$ which needs extensive expertise and requires constant update and maintenance.

b. Using space-technology based resources which can be easily procured and used [8]. The studies which utilized these methods were able to determine how to balance sun exposure to acquire vitamin D while avoiding over exposure. In Northern latitudes, it also helped in understanding the time of year wherein sun exposure will not be adequate for production of vitamin D [17] which can guide policies of fortification in those countries. These methods also help guide the population in a change of life-style for promoting sun exposure for optimal vitamin D. An additional advantage is that we acquire National-level estimates in a relatively short period of time.
In tropics where there is abundant sun shine, these estimates may also guide on preventing over exposure, while providing optimal vitamin D. Our estimates do show a latitude-dependent change in duration of exposure. The higher latitudes require more sun exposure for the production of same amount of vitamin D (1000IU). Researchers from a Northern latitude country-Canada $\left(56.1304^{\circ}\right.$ N) have also tried to estimate the feasibility of sun exposure for acquiring 1000 IU of vitamin D in fair skinned individuals who habitually expose $25 \%$ or $12.5 \%$ of their body surface area [8]. A latitude dependency of sun exposure time was observed in these studies with higher latitudes requiring more time of exposure for 1000 IU of vitamin D.

The current study showed a seasonal variability in the estimated duration of sun exposure for 1000 IU of vitamin D. The variabilities were as high as $133.1 \pm 125.24$ minutes in the Northern latitude (Srinagar) at noon, rendering it very difficult for the people residing in these areas to obtain adequate vitamin D from sun. It also shows that in a partially tropical country like India, the need for region-based guidelines should be recognized. Beyond tropics, depending solely upon sun exposure in all seasons seems to be unrealistic and alternate strategies such as fortification need to be thought about. Though our estimates show that adequate vitamin $\mathrm{D}$ can be acquired in a reasonable duration of around 30-35 minutes in locations lying within the tropics, it is intriguing to note that the prevalence estimates of vitamin D deficiency reported from epidemiological studies in these regions are about 50-70\%. This contrast may be due to various factors. Studies in India have shown a very high prevalence of deficiency among people with indoor occupations [18]. The deficiencies are comparatively lower in rural environments and among out- door workers $[19,20]$. Therefore, the duration of sun exposure appears to be a major restricting factor for acquiring vitamin $\mathrm{D}$. The optimal time for cutaneous production of vitamin D through sun exposure appears to be from 11. am to 2 pm [21].

Previously, one trial attempted to improve vitamin D of school children through sun exposure has reported no impact of 30 minutes exposure to sun with $10 \%$ BSA in winter at 22 degree $\mathrm{N}$ [22]. Interestingly, our estimates showed $44.8 \pm 48.18$ minutes are required at 22 degree $\mathrm{N}$ (Delhi) during winter for vitamin D production. Therefore, the estimates offer a possible explanation for lack of impact seen in the previous study and provide information on optimal duration to guide the decision on interventions aimed at improving vitamin D through sun exposure. However, we acknowledge that these estimates are approximations and need to be validated in real-life situations. Surface UVB instrument has been used by researchers from India to assess the amount of UVB during different seasons. Their findings showed that Northern latitude gets the maximum UVB during monsoon/autumn while southern and western zones recorded the maximum UVBI during summer. Our study corroborates with their findings with the lowest duration of sun exposure reported during monsoon in Srinagar, while in southern and western zones, the lowest exposure time required was in summer [22]. Another important aspect is the risk of overexposure which we tried to address through compiling data on UVI for the year after accounting for cloud wherever applicable. We found that 
majority of the days were free of the risk for over exposure. The maximum number of days with the risk of over-exposure was in Bangalore and Chennai, situated in the lower latitudes. The prevalence of skin cancer is also low in India constituting 1-2 \% of all diagnosed cancers [23] which corroborates with our finding. While the low prevalence of cancer

maybe a function of skin type and low BSA exposure, India, being a country with abundant rainfall in several parts, we cannot rule out that it could be a function of clouds which do attenuate the UV radiation to a considerable extent. Studies in the Northern latitudes had reported days wherein the UV Indices were less than 3 and therefore not capable of producing vitamin D [8]. This was not the case with Indian cities where majority of the days had a UVI greater than three.

\section{Limitations}

The present calculations do not account for aerosols which can also attenuate solar radiation.

\section{Conclusion}

An estimate for the duration of sun exposure required for $\mathrm{cu}-$ taneous synthesis of 1000 IU of vitamin D has been presented. On an average, 30-35 minutes of exposure was enough for $1000 \mathrm{IU}$ of vitamin D per day. However, seasonal and regional variations were high and therefore, region specific recommendations are required in the case of sun exposure. These estimates, although corroborate other lines of evidence on sun exposure and vitamin D, need to be validated in real-life situations.

\section{Acknowledgement}

The post doctoral research fellowship awarded to LA by Indian council of medical research, Government of India, is duly acknowledged.

\section{Reference}

1. DeLuca HF (1986) The metabolism and functions of vitamin D. Advances in experimental medicine and biology 196: 361-375.

2. Trilok Kumar G, Chugh R, Eggersdorfer M (2015) Poor Vitamin D Status in Healthy Populations in India: A Review of Current Evidence. International journal for vitamin and nutrition research Internationale Zeitschrift fur Vitamin-und Ernahrungsforschung. Journal international de vitaminologie et de nutrition 85(3-4): 185-201.

3. Shukla K, Sharma S, Gupta A, Raizada A, Vinayak K (2016) Current Scenario of Prevalence of Vitamin D Deficiency in Ostensibly Healthy Indian Population: A Hospital Based Retrospective Study. Indian journal of clinical biochemistry 31(4): 452-457.

4. Tsiaras WG, Weinstock MA (2011) Factors influencing vitamin D status. Acta dermato- venereologica 91(2): 115-124.

5. Suryanarayana P, Arlappa N, Sai Santhosh V, Rajendran Ananthan (2018) Prevalence of vitamin D deficiency and its associated factors among the urban elderly population in Hyderabad metropolitan city, South India. Annals of Human Biology 45(2): 133-139.

6. Nimitphong H, Holick MF (2013) Vitamin D status and sun exposure in southeast Asia. Dermato-Endocrinology 5(1): 34-37.
7. Engelsen O, Brustad M, Aksnes L, Lund E (2005) Daily duration of vitamin D synthesis in human skin with relation to latitude, total ozone, altitude, ground cover, aerosols and cloud thickness. Photochemistry and photobiology 81(6): 1287-1290.

8. Gill P, Kalia S (2015) Assessment of the feasibility of using sunlight exposure to obtain the recommended level of vitamin D in Canada. CMAJ open 3(3): 258-263.

9. (2016) UV station data based on satellite data. European space agency.

10. Webb AR, Slaper H, Koepke P, Schmalwieser AW (2011) Know your standard: clarifying the CIE erythema action spectrum. Photochemistry and photobiology 87(2): 483-486.

11. Fioletov VE, McArthur LJ, Mathews TW, Marrett L (2009) On the relationship between erythemal and vitamin $D$ action spectrum weighted ultraviolet radiation. Journal of photochemistry and photobiology B, Biology 95(1): 9-16.

12. Dowdy JC, Sayre RM, Holick MF (2010) Holick's rule and vitamin D from sunlight. The Journal of steroid biochemistry and molecular biology 121(1-2): 328-330.

13. Jani R, Palekar S, Munipally T, Ghugre P, Udipi S (2014) Widespread 25-Hydroxyvitamin D Deficiency in Affluent and Nonaffluent Pregnant Indian Women. BioMed Research International 2014(2): 892162.

14. Vanicek K, Frei T, Litynska Z, Schmalwieser A (1999) UV- Index for the Public. A guide for publication and interpretation of solar UV Index forecasts for the public prepared by the Working Group 4 of the COST713 Action UVB Forecasting. Brussels: COST- 713 Action.

15. Ministry of earth sciences GoI. System of Air Quality and Weather Forecasting and Research. In: Meteorology IIoT, (edn), Government of India, Pune, India.

16. Terushkin V, Bender A, Psaty EL, Engelsen O, Wang SQ, et al. (2010) Estimated equivalency of vitamin D production from natural sun exposure versus oral vitamin D supplementation across seasons at two US latitudes. Journal of the American Academy of Dermatology 62(6): 921-929.

17. Rhodes LE, Webb AR, Fraser HI, Kift R, Durkin MT, et al. (2010) Recommended summer sunlight exposure levels can produce sufficient ( $>$ or $=20 \mathrm{ng} \mathrm{ml}(-1)$ ) but not the proposed optimal ( $>$ or=32 $\mathrm{ng} \mathrm{ml}(-1)$ ) $25(\mathrm{OH}) \mathrm{D}$ levels at UK latitudes. The Journal of investigative dermatology 130(5):1411-1418.

18. Beloyartseva M, Mithal A, Kaur P, Sanjay Kalra, Manash P Baruah et al. (2012) Widespread vitamin D deficiency among Indian health care professionals. Archives of osteoporosis 7(1-2): 187-192.

19. Goswami R, Saha S, Sreenivas V, Singh N, Lakshmy R (2017) Vitamin D-binding protein, vitamin D status and serum bioavailable 25(OH)D of young Asian Indian males working in outdoor and indoor environments. Journal of bone and mineral metabolism 35(2): 177-184.

20. Harinarayan CV, Ramalakshmi T, Prasad UV, Sudhakar D, Srinivasarao PV, et al. (2007) High prevalence of low dietary calcium, high phytate consumption, and vitamin D deficiency in healthy south Indians. The American journal of clinical nutrition 85(4): 1062-1067.

21. Harinarayan CV, Holick MF, Prasad UV, Vani PS, Himabindu G (2013) Vitamin D status and sun exposure in India. Dermato-endocrinology 5(1): 130-141.

22. Marwaha RK, Yenamandra VK, Sreenivas V, et al. (2016) Regional and seasonal variations in ultraviolet B irradiation and vitamin D synthesis in India. Osteoporosis international 27(4): 1611-1617.

23. Deo SV, Hazarika S, Shukla NK, Kumar S, Kar M, et al. (2005) Surgical management of skin cancers: experience from a regional cancer centre in North India. Indian journal of cancer 42(3): 145-150. 
(C) (i) This work is licensed under Creative Submission Link: https://biomedres.us/submit-manuscript.php

\begin{tabular}{ll} 
BIOMEDICAL & Assets of Publishing with us \\
RESEARCHES & - Global archiving of articles \\
& - Immediate, unrestricted online access \\
& - Rigorous Peer Review Process \\
& - Authors Retain Copyrights \\
\hline hss: $2574-1241$ &
\end{tabular}

